\title{
Lung deposition of budesonide from Turbuhalera is twice that from a pressurized metered-dose inhaler P-MDI
}

\author{
L. Thorsson, S. Edsbäcker, T-B. Conradson
}

Lung deposition of budesonide from Turbuhaler ${ }^{\circledR}$ is twice that from a pressurized metereddose inhaler P-MDI. L. Thorsson, S. Edsbäcker, T-B. Conradson. CERS Journals Ltd 1994.

ABSTRACT: The pulmonary and systemic availability of budesonide after inhalation from a dry powder inhaler, Turbuhaler ${ }^{\circledR}$, and from a pressurized metered-dose inhaler (P-MDI) were compared in healthy volunteers.

Two different methods were used to assess pulmonary availability: 1) calculated from the systemic availability corrected for an oral availability of $13 \%(n=24)$; and 2) after blocking of gastrointestinal absorption by administration of a charcoal suspension $(n=13)$. An intravenous infusion of budesonide was used as a reference.

The systemic availability of budesonide, calculated as a geometric mean and expressed as percentage of the metered dose, was $38 \%$ for Turbuhaler ${ }^{\circledR}$ and $26 \%$ for P-MDI. The pulmonary availability, calculated using the first method, was $32 \%$ and $15 \%$ for Turbuhaler ${ }^{\circledR}$ and P-MDI, respectively; and, using the second method, $32 \%$ and $18 \%$, respectively.

The results of the present study indicate that administration of budesonide via Turbuhaler ${ }^{\circledR}$ gives rise to a lung deposition which is approximately twice that of a P-MDI, with less variability, but that systemic availability is only increased by approximately $50 \%$. Thus, the present data suggest that by administrating budesonide via Turbuhaler ${ }^{\circledR}$, instead of a P-MDI, the same degree of asthma control can be achieved with a lower dose, which, in turn, reduces the risk of undesired systemic effects.

Eur Respir J., 1994, 7, 1839-1844.
Astra Draco AB, P.O. Box 34, S-221 00

Lund Sweden.

Correspondence: L. Thorsson

Clinical Research and Development

Astra Draco AB

P.O. Box 34

S-221 00 Lund

Sweden

\section{Keywords: Budesonide}

lung deposition

powder inhaler

Turbuhaler ${ }^{\circledR}$

Received: February 71994

Accepted after revision June 261994
After inhalation, part of an inhaled drug is deposited in the lungs, whilst the major fraction is deposited in the oropharynx. If the mouth is not rinsed, this part is eventually swallowed, and absorbed from the gastrointestinal (GI) tract. Thus, both pulmonary and extrapulmonary absorption will contribute to the systemic availability of the inhaled drug.

Scintigraphic imaging is a commonly used technique to determine lung deposition after inhalation. Lung deposition can also be determined from urinary excretion of intact drug, provided that the contribution of orally deposited, and subsequently swallowed, drug can be accounted for, and that the drug is not metabolized in the lung [1]. One method of accounting for swallowed drug is to prevent GI absorption by using concomitant oral administration of activated charcoal. Another approach is to calculate the lung deposition from the systemic availability after inhalation, by subtracting the oral contribution.

After inhalation of clinically recommended doses of budesonide, the antiasthma effect may be explained by a local intrapulmonary action [2]. The drug is not metabolized in the lung tissue [3], and is rapidly and extensively absorbed [4]. Pharmacokinetic studies, performed in healthy subjects and in asthmatic children, have shown that budesonide has a high hepatic clearance $\left(>1 \mathrm{l} \cdot \mathrm{min}^{-1}\right)$ and a high first-pass metabolism, resulting in a low systemic availability (about 10\%) after oral dosing [4]. The major metabolites have no, or only marginal, glucocorticoid activity [5].

Budesonide, administrated via the inhalation flowdriven, multi-dose powder inhaler, Turbuhaler®, has been shown to be equally effective, in asthmatic children, as twice the dose from a P-MDI with a large volume spacer [6]. These results suggest that a larger fraction of budesonide is deposited in the lungs with Turbuhaler®. In a dose titration study in adult asthmatics, the dose required to obtain a similar control of asthma was $50 \%$ higher for beclomethasone dipropionate via a P-MDI than for budesonide via Turbuhaler® [7].

The aim of the present investigation was to compare the pulmonary and the systemic availability of budesonide after inhalation, as a dry powder via Turbuhaler ${ }^{\circledR}$ and as a suspension aerosol via P-MDI.

\section{Subjects}

Twenty four healthy subjects (12 women) participated in the study. Their mean age was 39 yrs (range 22-53 
yrs) and mean body weight $68 \mathrm{~kg}$ (range 45-92 kg). All subjects were healthy, as judged by routine physical examination, including haematology, blood chemistry tests and urinalysis. All subjects were moderate consumers of alcohol and nonsmokers, with the exception of one subject who occasionally smoked cigarettes. The study was approved by the Ethics Committee of the University of Lund and by the Medical Product Agency, Uppsala, Sweden. The trial was performed in accordance with the Declaration of Helsinki. The subjects were informed about the study, verbally and in writing, and gave their written consent to participation.

\section{Methods}

Two different methods were used to assess pulmonary availability: 1) in 24 healthy subjects, it was calculated from the systemic availability corrected for an assumed oral availability of 13\%; and 2) in 13 of the subjects, it was determined directly after blocking of gastrointestinal absorption by concomitant administration of a charcoal suspension.

All 24 subjects received an intravenous administration of budesonide as a reference, and all 24 were studied after inhalation of budesonide via Turbuhaler® and via P-MDI. Fifteen of the 24 subjects inhaled budesonide via Turbuhaler ${ }^{\circledR}$ and via $\mathrm{P}-\mathrm{MDI}$ after oral administration of an activated charcoal suspension. Fourteen of these 15 subjects also received an oral administration of budesonide (micronized powder in a capsule) with concomitant activated charcoal. This latter treatment was performed in order to permit a compensation to be made, in the availability calculations, for a small fraction of drug still being absorbed from the GI tract. The samples from one of these 14 subjects were lost and, thus, data from only 13 subjects could be completely evaluated.

The study was of an open, partially randomized, crossover design. The administration of oral budesonide, with concomitant charcoal suspension, was performed in a nonrandomized manner at the end of the study. The following single doses and formulations of budesonide (nominal doses) were administered, with intervals of at least 8 weeks between two consecutive study days: $1 \mathrm{mg}$ $(5 \times 200 \mu \mathrm{g})$ via Pulmicort $\AA$ Turbuhaler $\AA$ or Pulmicort $\AA$ P-MDI, with $(n=15)$ and without $(n=24)$ concomitant charcoal administration; $0.5 \mathrm{mg}$ intravenous solution $(n=24)$; and $4 \mathrm{mg}$ in gelatine capsules $(n=14)$, for oral administration, with concomitant administration of charcoal. The intravenous formulation of budesonide and the gelatine capsules containing budesonide for oral administration were manufactured by the Department of Pharmaceutical Development at Astra Draco AB. Carbomix (Medica Pharmaceutical) charcoal suspension (200 $\mathrm{mg} \cdot \mathrm{ml}^{-1}$ ) was used for charcoal administration.

Following all budesonide administrations without charcoal, the mouth was immediately rinsed with $200 \mathrm{ml}$ of water, which was then swallowed. When administrations with concomitant charcoal administration were performed, the mouth was thoroughly rinsed with $2 \times 25 \mathrm{ml}$ of charcoal suspension, which was swallowed immediately before drug administration. The charcoal administration was repeated at $5 \mathrm{~min}, 1$ and $2 \mathrm{~h}$ after drug administration.

On the treatment days, the subjects arrived at the clinic after an overnight fast. No alcohol was allowed for 24 $\mathrm{h}$ before each treatment. A standardized breakfast was served $0.5 \mathrm{~h}$ before the start of drug administration. The subjects had to abstain from eating for $4 \mathrm{~h}$, and from drinking for $2 \mathrm{~h}$ after each drug administration.

The inspiratory flow and volume of each inhalation for Turbuhaler® and from P-MDI were recorded using a pulmonary function analyser (Vitalograph ${ }^{\circledR}$ Compact, Vitalograph Ltd, UK) with a specially designed interface. The subjects were trained to breathe out to residual volume, and then to inhale at a flow of $60 l \cdot \mathrm{min}^{-1}$ for Turbuhaler ${ }^{\circledR}$, and $30 \mathrm{l} \cdot \mathrm{min}^{-1}$ for P-MDI; and, for the latter, to actuate the dose, with the mouth closed around the adapter, during inhalation. After inhalation, the breath was held for $5 \mathrm{~s}$ before a slow exhalation was performed through a Respirgard ${ }^{\circledR}$ filter. The subject then breathed gently through the filter until the next dose was administered. A noseclip was used to prevent nosebreathing. A total nominal dose of $1 \mathrm{mg}$ was administered in five doses of $200 \mu \mathrm{g}$, taken at intervals of 40s. The Turbuhaler $\AA$ inhalers were primed by removing five doses by vacuum suction, using a separate mouthpiece, before use by the subject. The P-MDI was primed, prior to the study administration, by actuating five doses into a plastic bag, using a separate adapter. The Turbuhaler® inhalers and the P-MDIs were individually characterized with regard to drug output. The metered-dose was calculated as a mean of the doses leaving the dose reservoirs (standard in vitro measurement using a mean of five doses from Turbuhaler ${ }^{\circledR}$ and a mean of 10 doses from P-MDI). The amount of drug retained in the mouthpiece/adapters and exhalation filters was determined by thorough rinsing with ethanol $(99.5 \%)$ containing an internal standard, and subsequent liquid chromatography.

The intravenous dose was administered as an infusion over 9 min into an antecubital vein of the arm not used for blood sampling. The dose was estimated by weighing the syringe before and after infusion. The oral dose, administere as micronized powder in a gelatine capsule, was specified by weighing the amount of budesonide powder put into each capsule.

Blood samples were obtained from an indwelling catheter inserted into an antecubital vein. The plasma was separated by centrifugation $(1,500 \times \mathrm{G})$ for $10 \mathrm{~min}$ and was then immediately frozen at $-20^{\circ} \mathrm{C}$ until analysed. The assay of budesonide in plasma was based on a combination of liquid chromatography and mass spectrometry (LC-MS) [8].

Pharmacokinetic parameters were calculated according to routine methods. The systemic availability was calculated as the ratio of inhalation to intravenous area under the plasma concentration versus time curve (AUC). The individual systemic availability data were log-transformed and means were expressed as geometric means with $95 \%$ confidence limits. A pairwise comparison of the treatments was performed using a multiplicative statistical model. For all other parameters, means are expressed as arithmetic means. 


\section{Pulmonary availability: method with assumed GI availability}

The amount of budesonide deposited in and absorbed from the lung $\left(\mathrm{F}_{\text {lung }}\right)$ was calculated from the systemic availability $\left(\mathrm{F}_{\text {syst }}\right)$, assuming an oral availability $\left(\mathrm{F}_{\text {oral }}\right)$ of $13 \%$, using the equation:

$$
F_{\text {lung }}=\frac{\mathrm{F}_{\text {syst }}-\mathrm{F}_{\text {oral }}(1-\mathrm{ret})}{1-\mathrm{F}_{\text {oral }}}
$$

where "ret" is the fraction of the metered dose retained in the device and exhaled onto the filters. The oral availability of $13 \%$ was obtained in a previous in-house study, in which 11 healthy subjects received an intravenous administration of budesonide $(0.5 \mathrm{mg})$ and an oral administration of budesonide ( $4 \mathrm{mg}$ in gelatine capsules). The value of $13 \%$ is the highest mean value which has been found for the oral availability of budesonide, and was used in the present study in order to estimate the highest possible GI contribution to the systemic availability. In previously published studies, the oral availability of budesonide has been estimated to be $6 \%$ [9] and $11 \%$ [10].

\section{Pulmonary availability: charcoal-block method}

Pulmonary availability was determined in 13 of the subjects who were given charcoal suspensions in conjunction with budesonide administrations. In order to obtain pulmonary availability data, the systemic availability values were adjusted individually for drug absorbed from the GI tract. The GI tract absorption data were obtained from the oral administration of budesonide with concomitant charcoal suspension.

\section{Results}

Analysis of individual Turbuhaler ${ }^{\circledR}$ devices revealed that, of the nominal dose of $1,000 \mu \mathrm{g}(5 \times 200 \mu \mathrm{g})$, a mean $( \pm \mathrm{SD})$ of $891 \pm 83 \mu \mathrm{g}$ left the dose reservoir (metered dose), $191 \pm 45 \mu \mathrm{g}$ was retained in the mouthpiece, and $0-14 \mu \mathrm{g}$ (range) was exhaled. Corresponding figures for individual P-MDI were $935 \pm 69 \mu \mathrm{g}$ (metered dose), $72 \pm 33$ $\mu \mathrm{g}$ retained in the adapter, and $0-15 \mu \mathrm{g}$ exhaled.

The inhalations were performed under controlled conditions. The flows (mean $\pm \mathrm{SD}$ ) were $52 \pm 13 l \cdot \mathrm{min}^{-1}$ for Turbuhaler ${ }^{\circledR}$ and $40 \pm 19 l \cdot \mathrm{min}^{-1}$ for P-MDI administrations, $0.5 \mathrm{~s}$ after the start of the inhalation, and $48 \pm 14 \mathrm{l} \cdot \mathrm{min}^{-1}$ and $29 \pm 8 l \cdot \mathrm{min}^{-1}$, respectively, after $3.0 \mathrm{~s}$. The inhaled volumes were $3.2 \pm 0.7 l$ for Turbuhaler ${ }^{\circledR}$ and $2.5 \pm 1.1 l$ for the P-MDI administrations.

No budesonide was detected in any of the plasma samples taken immediately before each administration.

\section{Systemic availability}

Figure 1 shows the mean plasma concentrations after intravenous dosing and after dosing via inhalation with Turbuhaler ${ }^{\circledR}$ and P-MDI, without charcoal. The peak budesonide plasma concentration (Cmax) was higher

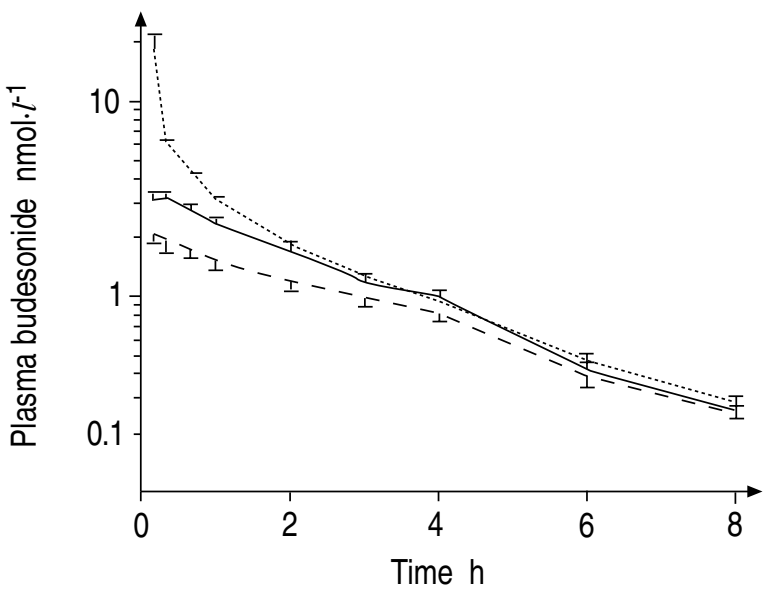

Fig. 1. - Mean plasma concentrations (SEM) of budesonide after inhalation from Turbuhaler ${ }^{\circledR}(-)(1 \mathrm{mg})$ and pressurized metereddose inhaler (P-MDI) (__ $\quad(1 \mathrm{mg})$, with intravenous infusion as a reference $(. . . . . . . . .$.$) , in 24$ healthy volunteers.

after inhalation via Turbuhaler ${ }^{\circledR}, 3.5 \mathrm{nmol} \cdot l^{-1}$ (range $\left.2.2-5.6 \mathrm{nmol} \cdot l^{-1}\right)$ attained at $0.3 \mathrm{~h}$ (range $\left.0.2-0.7 \mathrm{~h}\right)$, than for the P-MDI, $2.3 \mathrm{nmol} \cdot l^{-1}$ (range $0.7-4.0 \mathrm{nmol} \cdot l^{-1}$ ) attained at $0.5 \mathrm{~h}$ (range $0.2-3.0 \mathrm{~h})$. The Turbuhaler ${ }^{\circledR}$ to P-MDI Cmax quotient was estimated to be 1.7 (95\% confidence limits (CL) 1.4-2.0). Mean absorption time was $1.0 \mathrm{~h}$ (range $0.3-1.8 \mathrm{~h}$ ) for Turbuhaler ${ }^{\circledR}$ and $1.4 \mathrm{~h}$ (range $0.8-2.6 \mathrm{~h}$ ) for the P-MDI.

After inhalation via Turbuhaler ${ }^{\circledR}, 38 \%$ (geometric mean, range $23-62 \%$ ) of the metered-dose was systemically available, and after inhalation via P-MDI, the value was $26 \%$ (geometric mean, range $15-53 \%$ ). The Turbuhaler ${ }^{\circledR}$ to P-MDI systemic availability quotient was estimated to be 1.5 (95\% CL 1.3-1.7).

From intravenous data, the plasma half-life of budesonide was calculated as $2.3 \mathrm{~h}$ (range 1.7-3.4 h). The plasma concentration curves entered the terminal phase between 1 and $3 \mathrm{~h}$. Plasma clearance and volume of distribution $\left(\mathrm{V}_{\mathrm{ss}}\right)$ were $1.34 l \cdot \mathrm{min}^{-1}$ (range $0.94-1.98 l \cdot \mathrm{min}^{-1}$ ) and $2.69 l \cdot \mathrm{kg}^{-1}$ (range $1.41-5.02 l \cdot \mathrm{kg}^{-1}$ ), respectively.

\section{Pulmonary availability: method with assumed GI availability}

The pulmonary availability, calculated relative to metered-doses and assuming an oral availability of $13 \%$, was $32 \%$ (geometric mean, range 16-59\%) for Turbuhaler ${ }^{\circledR}$ and $15 \%$ (range $3-47 \%$ ) for P-MDI. The Turbuhaler® to P-MDI pulmonary availability quotient was estimated to be 2.2 (95\% CL 1.6-2.9). The amount of drug absorbed from the lung and the contribution, to the systemic circulation, of drug absorbed via the GI tract is presented graphically in figure 2 . From the amount of drug entering the systemic circulation via the GI tract, it can be calculated that this fraction $(6 / 38$ for Turbuhaler ${ }^{\circledR}$ and $11 / 26$ for P-MDI) is about 2.7 times higher after inhalation via P-MDI than after inhalation via Turbuhaler®.

The variability of the pulmonary availability, relative to the metered-dose, was significantly lower $(\mathrm{p}=0.0006)$ for Turbuhaler®, with a coefficient of variation $(\mathrm{CV})$ of $32.8 \%$ as compared with a $\mathrm{CV}$ of $76.7 \%$ for P-MDI. 


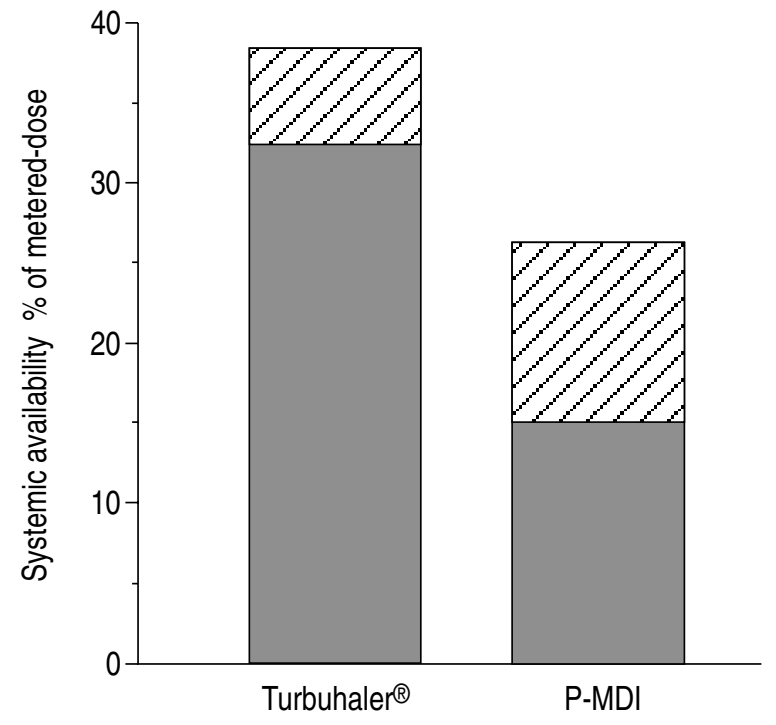

Fig. 2. - The amount of drug absorbed from the lung and the contribution to the systemic circulation of drug absorbed from the gastrointestinal (GI) tract after administration of budesonide via Turbuhaler ${ }^{\circledR}$ and via the pressurized metered-dose inhaler (P-MDI). Metered dose averaged $891 \mu \mathrm{g}$ for Turbuhaler ${ }^{\circledR}$ and $935 \mu \mathrm{g}$ for PMDI. Lung deposition from Turbuhaler ${ }^{\circledR}$ is approximately twice that of P-MDI, whereas the GI contribution to the systemic availability is only half that of P-MDI. Thus, Turbuhaler ${ }^{\circledR}$ has a more beneficial ratio of lung deposition to systemic absorption. $\square$ : via GI tract; $\square$ : via lung.

\section{Pulmonary availability: charcoal-block method}

Plasma concentrations of budesonide, in the $13 \mathrm{sub}-$ jects who received all three administrations (P-MDI, Turbuhaler® and oral capsule) with concomitant charcoal suspension are illustrated in figure 3 . With respect to Cmax and Tmax, the plasma budesonide profiles are virtually identical, regardless of the concomitant use of

a)

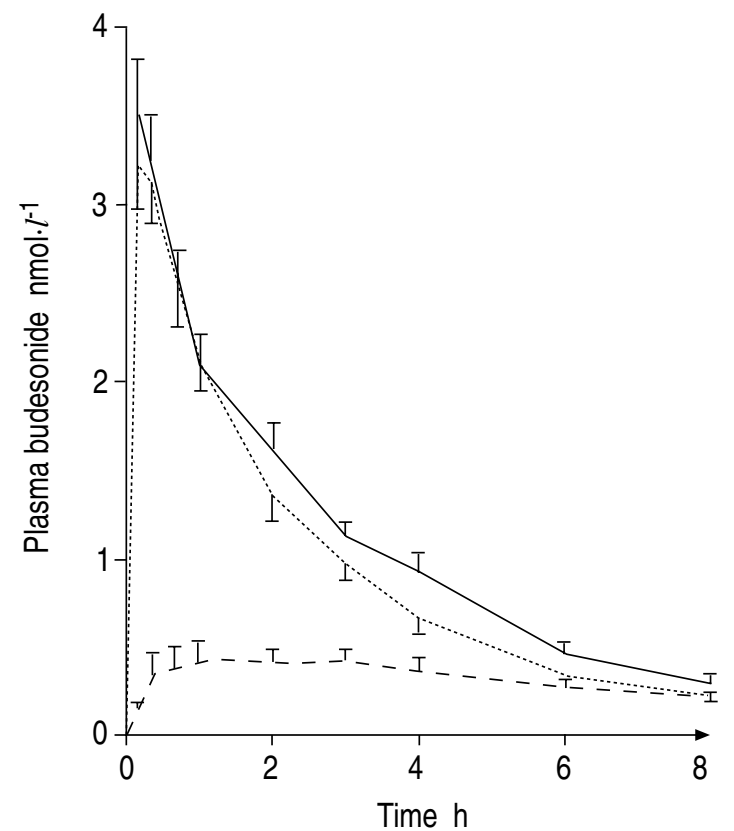

charcoal suspension. The oral availability of budesonide, after concomitant charcoal administration, was found to be $2.5 \%$. With an oral availability of $13 \%$ without charcoal, the preventive effect of charcoal on budesonide absorption can be estimated to be approximately $80 \%$. The pulmonary availability, calculated using the metered doses from Turbuhaler® and P-MDI, with concomitant administration of charcoal, and compensated for the contribution of orally absorbed drug, was $32 \%$ for Turbuhaler® and $18 \%$ for the P-MDI. The Turbuhaler® to P-MDI pulmonary availability quotient was estimated to be 1.8 (95\% CL 1.3-2.5).

\section{Discussion}

In this study, the pulmonary and systemic availability of budesonide after inhalation from a dry powder inhaler, Turbuhaler®, and from a P-MDI were compared. The pulmonary availability was $32 \%$ for Turbuhaler ${ }^{\circledR}$ and $15 \%$ for P-MDI (assuming an oral availability of $13 \%$ ). The systemic availability of budesonide was $38 \%$ from Turbuhaler ${ }^{\circledR}$, and $26 \%$ from P-MDI. In a gammascintigraphic study on lung deposition of $99 \mathrm{~m}$ Tc-labelled budesonide via Turbuhaler ${ }^{\circledR}, 27.7 \%$ of the metered dose was deposited in the lungs at a peak inspiratory flow of $58 \mathrm{l} \cdot \mathrm{min}^{-1}$ [11]. Similar results were obtained in the present study, irrespective of the method used for calculating pulmonary availability.

The pulmonary availability for Turbuhaler® was about twice that for the P-MDI. The systemic availability of the metered dose of budesonide after inhalation via Turbuhaler ${ }^{\circledR}$ is about $50 \%$ higher than that seen after inhalation via the P-MDI. However, with Turbuhaler®, a significantly larger fraction, 2.2 times (95\% CL 1.6-2.9),

b)

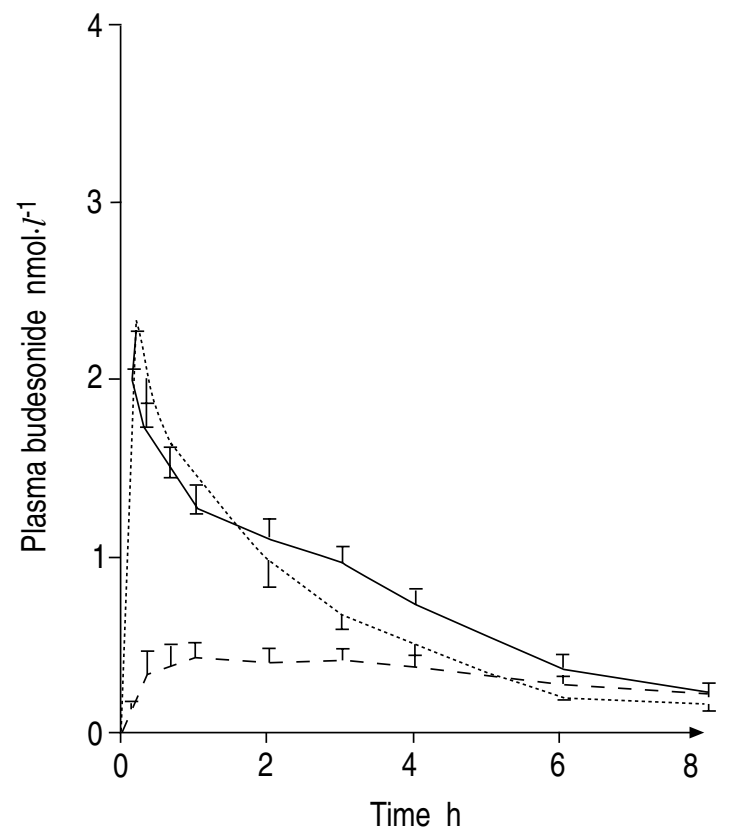

Fig. 3. - Mean plasma concentrations (SEM) of budesonide after inhalation from: a) Turbuhaler ${ }^{\circledR}(1 \mathrm{mg})$; or b) pressurized metered-dose inhaler

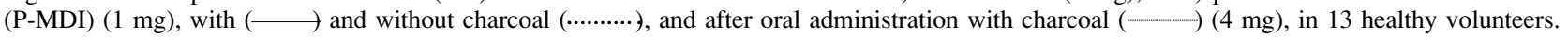


of the metered-dose was deposited in the lungs than with P-MDI. The contribution from pulmonary absorbed drug to the overall systemic availability (lung/total $=\mathrm{L} / \mathrm{T}$ ratio), calculated for all 24 subjects using the administrations without charcoal and an oral availability of $13 \%$, was $84 \%$ for Turbuhaler ${ }^{\circledR}$ and $58 \%$ for the P-MDI.

Metabolic inactivation in the lung has not been demonstrated for any of the inhaled glucocorticosteroids currently available. Thus, when a glucocorticosteroid is inhaled into the lungs, systemic absorption of the drug is inevitable. As a consequence of an increased lung deposition of the drug, not only an increased pulmonary effect, but also an increased systemic absorption should occur. However, an increased lung deposition is accompanied by a reduced oropharyngeal deposition, i.e. a reduction in the fraction of the dose which is systemically available via the GI tract, and which does not contribute to the local effect in the lung. Since budesonide via Turbuhaler®, has a high first-pass metabolism and can be administered via an inhalation system which gives a high degree of lung deposition, the GI contribution to the systemic availability of budesonide is negligible.

The relationship between P-MDI and Turbuhaler ${ }^{\circledR}$ obtained in the present study is in agreement with a previous clinical study in asthmatic children, in which budesonide via Turbuhaler@ was found to be equally effective as twice the dose from a P-MDI with a large volume spacer [6]. Holding chambers and spacers are used to decrease the oropharyngeal deposition from a PMDI, in order to avoid local side-effects such as hoarseness and oropharyngeal candidiasis. In a recent study in 154 patients using a steroid P-MDI with spacer, the frequency of local side-effects, mainly hoarseness, was reduced from 21 to $6 \%$ when transferring from P-MDI to budesonide via Turbuhaler® [12].

It cannot be ruled out that a less strict and less wellcontrolled inhalation procedure, than that used in the present study, could have resulted in a difference between Turbuhaler® and P-MDI which would have been even more accentuated. An inhalation flow of $60 l \cdot \mathrm{min}^{-1}$ is clinically relevant for Turbuhaler® as most asthmatic patients have no difficulties, in general, in reaching this flow [13]. In acute asthma, 98\% of the patients were able to generate a peak inspiratory flow (PIF) of $>30$ $l \cdot \mathrm{min}^{-1}$ through Turbuhaler® $\left(\right.$ mean \pm SD $\left.60 \pm 20 l \cdot \mathrm{min}^{-1}\right)$, which permits efficient use of the inhaler [14]. Virtually all children aged $\geq 6$ yrs, and about $75 \%$ of children $<6$ yrs, were able to generate a PIF of $\geq 28 \mathrm{l} \cdot \mathrm{min}^{-1}$ through Turbuhaler ${ }^{\circledR}$, and should, thus, benefit from budesonide administered via Turbuhaler® [15]. The inhalation flow of $30 \mathrm{l} \cdot \mathrm{min}^{-1}$ for the P-MDI was chosen in order to optimize the lung deposition [16].

The variability (coefficient of variation) for the in vitro measurement of the metered dose was $7 \%$ for P-MDI $(935 \pm 69 \mu \mathrm{g})$ and $10 \%$ for Turbuhaler ${ }^{\circledR}(891 \pm 83 \mu \mathrm{g})$. The in vivo results for pulmonary availability were vice versa, with a variability for Turbuhaler ${ }^{\circledR}$ which was significantly lower (approximately twice) than that of the P-MDI. This difference between in vitro and in vivo results is probably due to the fact that the relatively small variability seen under standardized in vitro conditions becomes less important when the biological variation e.g. of inhalation technique, is added. In the present study, the inhalation technique was carefully monitored, thus minimizing variability. In clinical practice, the varia-bility may be anticipated to be even larger.

In conclusion, the results of the present study indicate that administration of budesonide via Turbuhaler ${ }^{\circledR}$ gives rise to a lung deposition which is approximately twice that of a P-MDI, with less variability. Despite the doubled lung deposition from Turbuhaler ${ }^{\circledR}$, systemic availability is only increased by approximately $50 \%$, as compared with a P-MDI. Thus these data suggest that by administrating budesonide via Turbuhaler ${ }^{\circledR}$, instead of a P-MDI, the same degree of asthma control can be achieved with a lower dose, which, in turn, further reduces the risk of undesired systemic effects.

Acknowledgement: The authors wish to thank A. Blomqvist for analysing budesonide in the plasma samples.

\section{References}

1. Borgström L, Nilsson M. A method for determination of the absolute pulmonary bioavailability of inhaled drugs: Terbutaline. Pharm Res 1990; 7 (10): 10681070 .

2. Toogood JH, Frankish CW, Jennings BH, et al. A comparison of the antiasthmatic efficacy of inhaled versus oral budesonide. J Allergy Clin Immunol 1990; 85: 872-880.

3. Andersson P, Ryrfeldt A. Biotransformation of the topical glucocorticoids budesonide and beclomethasone $17 \alpha$, 21-dipropionate in human liver and lung homogenate. $J$ Pharm Pharmacol 1984; 36: 763-765.

4. Ryrfeldt Å, Andersson P, Edsbäcker S, Tönnesson M, Davies D, Pauwels R. Pharmacokinetics and metabolism of budesonide, a selective glucocorticoid. Eur J Respir Dis 1982; 63 (Suppl. 122): 86-95.

5. Dahlberg E, Thalén A, Brattsand R, et al. Correlation between chemical structure, receptor binding, and biological activity of some novel, highly active, $16 \alpha, 17 \alpha-$ acetyl substituted glucocorticoids. Mol Pharmacol 1984; 25: 70-78.

6. Agertoft L, Pedersen S. Importance of inhalation device on the effect of budesonide. Arch Dis Child 1993; 69: 130-133.

7. Brambilla C, Braunstein G, Lacronique J, Allaert F, Godard P, Duroux P. Comparison between beclomethasone dipropionate by metered-dose inhaler and budesonide by Turbuhaler® in asthmatic adults. Am Rev Respir Dis 1992; 145: A737.

8. Lindberg C, Blomqvist $\AA$, Paulson J. Determination of $(22 R, S)$ budesonide in human plasma by automated liquid chromatography/thermospray mass spectrometry. Biol Mass Spectrom 1992; 21: 525-533.

9. Dahlström K, Edsbäcker S, Conradson T-B. Rectal and oral bioavailability of budesonide in man. Hellenic $J$ Gastroent 1992; 5 (Suppl.): A297.

10. Ryrfeldt Å, Andersson P, Edsbäcker S, Tönnesson M, Davies D, Pauwels R. Pharmacokinetics and metabolism of budesonide, a selective glucocorticoid. Eur J Respir Dis 1982; 63 (Suppl. 122): 86-95.

11. Engel T, Heinig JH, Madsen F, Nikander K. Peak inspiratory flow and inspiratory vital capacity of patients with asthma measured with and without a new dry-powder 
inhaler device (Turbuhaler()). Eur Respir J 1990; 3: 1037-1041.

12. Selroos O, Backman R, Forsén K-O, et al. Local sideeffects during four years treatment with inhaled corticosteroids: a comparison between metered-dose inhalers and Turbuhaler ${ }^{\circledR}$. Allergy (in press).

13. Dolovich M, Ruffin RE, Roberts R, Newhouse MT. Optimal delivery of aerosols from metered-dose inhalers. Chest 1981; 6 (Suppl.): 911-915.

14. Brown PH, Greening AP, Crompton GK. Peak in- spiratory flow rates in acute asthma: are they adequate for efficient use of a Turbuhaler®? Thorax 1992; 47: 239.

15. Pedersen S, Hansen OR, Fuglsang G. Influence of inspiratory flow rate upon the effect of a Turbuhaler®. Arch Dis Child 1990; 65: 308-310.

16. Borgström L, Bondesson E, Morén F, Trofast E, Newman SP. Lung deposition of budesonide inhaled via Turbuhaler®. A comparison with terbutaline sulphate. Eur Respir J 1994; 7: 69-73. 